\title{
Esverdeando a cadeia de suprimentos: algumas evidências de empresas localizadas no Brasil
}

\section{Greening the supply chain: evidences of firms in Brazil}

\author{
Ana Beatriz Lopes de Sousa Jabbour ${ }^{1}$ \\ Fernanda de Souza Azevedo' \\ Ariana Fernandes Arantes ${ }^{1}$ \\ Charbel José Chiappetta Jabbour ${ }^{1}$
}

\begin{abstract}
Resumo: O objetivo deste artigo é identificar e analisar como práticas de Green Supply Chain Management (GSCM) estão sendo adotadas por empresas de alta tecnologia localizadas no Brasil, a fim de gerar diretrizes de como empresas similares podem proceder para incorporar iniciativas de GSCM. A pesquisa foi desenvolvida a partir de estudo de casos com empresas representativas desse setor. Como principais resultados, destacam-se: (a) a estrutura da cadeia de suprimentos pode afetar a adoção e a forma como se adotam práticas de GSCM; (b) a legislação ambiental brasileira e as diretivas internacionais são muito importantes para impulsionar a adoção de práticas de GSCM; e (c) para cada uma das seis práticas de GSCM, apresentam-se sugestões de como empresas similares podem adotá-las com maior êxito.
\end{abstract}

Palavras-chave: Sustentabilidade. Green Supply Chain Management. Implementação de práticas. Setor de alta tecnologia. Brasil.

\begin{abstract}
The purpose of this article is to identify and analyze how Green Supply Chain Management (GSCM) practices have been adopted by high-tech companies located in Brazil in order to create guidelines to support similar companies to incorporate GSCM initiatives. This research was based on case studies carried out in some representative companies in this sector. The main results are: (a) the supply chain structure can affect both the adoption of GSCM practices and the way they are adopted, $(b)$ the Brazilian environmental legislation and international policies are very important to boost the adoption of GSCM practices, and (c) based on the results obtained, for each one of the six GSCM practices, suggestions for a more appropriate adoption are offered to similar companies.
\end{abstract}

Keywords: Sustainability. Green Supply Chain Management. Implementation of practices. High technology sector. Brazil.

\section{Introdução}

Aspectos como globalização da economia, aumento da conscientização ambiental dos stakeholders, legislação e regulação ambiental têm resultado em mudanças nas empresas no sentido de perceberem a importância que as questões ambientais têm assumido para a elaboração de suas estratégias competitivas e a importância de expandir o escopo da adoção de práticas ambientalmente adequadas para a cadeia de suprimentos, a fim de cobrir o ciclo de vida de seus produtos (MARTÍ; SEIFERT, 2013; GOVINDAN; CHENG, 2011).

No contexto brasileiro, a Nova Política Nacional dos Resíduos Sólidos (PNRS) (BRASIL, 2010), que instituiu a responsabilidade compartilhada entre os fabricantes, importadores, distribuidores, comerciantes, cidadãos e titulares de serviços de manejo dos resíduos sólidos urbanos na Logística Reversa dos resíduos e embalagens pós-consumo, pode ser um importante vetor para mudanças das estratégias competitivas das empresas localizadas no Brasil. Pela Lei, tanto o setor público quanto as empresas locais e multinacionais deverão se adequar para adotar práticas de green supply chain management (GSCM), em consequência da logística reversa. Conforme Lai e Wong (2012), a pressão institucional é um importante indutor da adoção de práticas mais avançadas de gestão ambiental, como a GSCM.

Green supply chain management (GSCM) é uma abordagem moderna de gestão ambiental. Tem como pressuposto que as empresas não agem sozinhas, mas sim se interligando desde fornecedores de matéria-prima até os consumidores finais, formando

\footnotetext{
${ }^{1}$ Departamento de Engenharia de Produção, Faculdade de Engenharia de Bauru, Universidade Estadual Paulista - UNESP, Av. Engenheiro Luiz Edmundo Carrijo Coube, 14-01, Vargem Limpa, CEP 17033-360, Bauru, SP, Brasil, e-mails: abjabbour@ feb. unesp.br; fer_sazevedo@hotmail.com; arianafarantes@hotmail.com; prof.charbel@gmail.com
} 
as chamadas cadeias de suprimentos, que devem estar preocupadas em atender às exigências do mercado com a adoção de princípios de gestão ambiental (SEURING et al., 2008).

As pesquisas comunicadas em revistas nacionais sobre o tema GSCM até o momento, encontradas em buscas na base de dados Scielo, ainda são predominantemente teóricas, com foco em pesquisas bibliométricas como as de Dias, Labegalini e Csillag (2012) e Brito e Berardi (2010). Portanto, há oportunidades da condução de estudos empíricos focando o contexto brasileiro, principalmente, porque, sejam as pesquisas nacionais ou internacionais, a discussão de como se adotam práticas de GSCM ainda é temática carente.

Considerando o atual contexto brasileiro da Nova Política Nacional de Resíduos Sólidos e a oportunidade da condução de pesquisas empíricas, tem-se como questão de pesquisa: Como práticas GSCM estão sendo adotadas por empresas de alta tecnologia localizadas no Brasil? Portanto, este artigo tem por objetivo identificar e analisar como práticas de GSCM estão sendo adotadas em empresas de alta tecnologia localizadas no Brasil, a fim de gerar diretrizes de como empresas similares podem proceder para incorporar iniciativas de GSCM. Para que o objetivo seja alcançado, foram realizados oito casos com empresas de alta tecnologia, pois o setor eletroeletrônico é um dos setores econômicos que tende a ser afetado pela PNRS.

Este artigo está estruturado em cinco seções, sendo que a primeira, a Introdução, contextualiza a pesquisa e destaca o objetivo do estudo; a segunda é o Referencial Teórico, que destaca os principais fundamentos para a condução da pesquisa empírica; a terceira é o Método de Pesquisa, que apresenta os procedimentos de coleta e análise dos dados pesquisados; a quarta, Resultados e Discussões, detalha como as empresas estudadas adotam práticas de GSCM; e a quinta, Conclusões, realça as contribuições da pesquisa e as diretrizes de implementação de práticas de GSCM.

\section{Estudos prévios}

GSCM corresponde a atividades ou ações tomadas para reduzir ou eliminar o impacto ambiental da cadeia de suprimentos. Portanto, pode incluir qualquer esforço ambiental voltado para a criação, desenvolvimento, produção e/ou entrega de um produto para o usuário final (GOLICIC; SMITH, 2013). Uma forma de compreender GSCM é mediante análise da adoção de suas práticas de gestão.

A literatura aponta para várias práticas de GSCM, nesse sentido, foi necessária a escolha de algumas delas, para fazerem parte do questionário utilizado na pesquisa empírica. Por isso, foi escolhida a classificação de Zhu, Sarkis e Lai (2008), que validaram os constructos das práticas de GSCM.
Essas práticas são: gestão ambiental interna; compras verdes; cooperação com os clientes; ecodesign; e recuperação de investimentos. Além dessas, incluiu-se a prática de logística reversa, uma vez que Sarkis, Zhu e Lai (2011) e Srivastava (2007) a destacam como importante para a composição de uma cadeia de suprimentos verde.

As práticas de GSCM podem ser consideradas como internas e externas, sendo, as internas, a gestão ambiental interna, ecodesign e recuperação de investimentos e, as externas, compras verdes e cooperação com os clientes (ZHU; SARKIS, 2004; ZHU et al., 2008).

A prática de gestão ambiental interna corresponde a algumas atividades do dia a dia da empresa voltadas à melhoria ambiental da fábrica, como apoio da alta e média gerência; cooperação interfuncional para a implementação de melhorias ambientais; desenvolvimento de um Sistema de Gestão Ambiental; auditoria ambiental e proposição de metas ambientais para a fábrica (ZHU; SARKIS; LAI, 2008). A gestão ambiental interna é identificada como um precursor necessário para a implementação de compras verdes, cooperação com os clientes, ecodesign e recuperação de investimentos (ZHU; SARKIS; LAI, 2012b; GREEN JUNIOR et al., 2012).

Zsidisin e Siferd (2001) definem compras verdes como um conjunto de políticas, ações e relações formadas em resposta às preocupações associadas com o meio ambiente, afetando a forma de seleção, avaliação e desenvolvimento de fornecedores. Segundo Min e Galle (2001), compras verdes têm como objetivo reduzir insumos, desperdícios e promover a reciclagem dos produtos.

A cooperação com os clientes apresenta-se como uma forma de troca de conhecimentos entre as partes, o que permite o planejamento e a definição de metas para o progresso ambiental (ELTAYEB; ZAILANI; RAMAYAH, 2011). A cooperação com o cliente está associada ao desempenho do produto nos aspectos de conformidade às especificações e à durabilidade, o que inclui a qualidade ambiental dos insumos (VACHON; KLASSEN, 2008). Segundo Zhu, Sarkis e Lai (2008), a cooperação com o cliente inclui ecodesign, produção mais limpa e embalagem verde.

$\mathrm{O}$ ecodesign visa gerar melhorias ambientais desde o projeto e o processo do produto (VACHON; KLASSEN, 2006). Para a execução do ecodesign, é necessário o design de produtos para a redução de materiais/energia, para a reutilização e reciclagem de componentes e para evitar o uso ou fabricação de produtos perigosos (ZHU; SARKIS; LAI, 2008). O ecodesign está dividido em duas categorias: produto e embalagem (DIABAT; GOVINDAN, 2011). E, neste processo, pode haver a participação de fornecedores (HSU; HU, 2008) e de clientes. 
A prática de recuperação de investimentos refere-se ao uso estratégico da reciclagem, reconversão e revenda para obter valor de materiais e produtos ao transformar ativos excedentes, ativos ociosos e equipamentos usados (quando é comprado um novo) em receita ao recuperar os gastos (ZHU et al., 2008).

Logística reversa é o processo de planejamento, implementação e controle do fluxo eficiente e de baixo custo de materiais obsoletos, em processo de inventário e de bens após o final de sua vida útil, do ponto de consumo até o ponto de origem, com o objetivo de recapturar valor ou dar a eliminação adequada (SHERIFF; GUNASEKARAN; NACHIAPPAN, 2012). O canal reverso inclui coleta, separação, densificação, processo de transição e reintegração (SARKIS, 2003).

As práticas de GSCM (Figura 1) possuem importância relativa entre si. A seguir, por intermédio de alguns estudos, relata-se esse fato.

Em geral, as práticas internas de GSCM são mais adotadas que as práticas externas devido à falta de conhecimento ou de ferramentas (ZHU; SARKIS, 2004; ZHU; SARKIS; LAI, 2007).

Zhu e Sarkis (2004, 2006), Hoejmose, Brammer e Millington (2012) e Zhu, Sarkis e Lai (2012b) detectaram que a gestão ambiental interna, em especial o suporte da alta administração, e a recuperação de investimentos são aspectos críticos e amplamente adotados, respectivamente. Para Zhu, Sarkis e Lai (2012b), empresas são proativas em termos de adoção de práticas de GSCM quando, além de ter iniciativas consolidadas de gestão ambiental interna e recuperação de investimentos, possuem ações de ecodesign.

Hsu e Hu (2008) constataram que a gestão do fornecedor e o envolvimento organizacional (apoio da

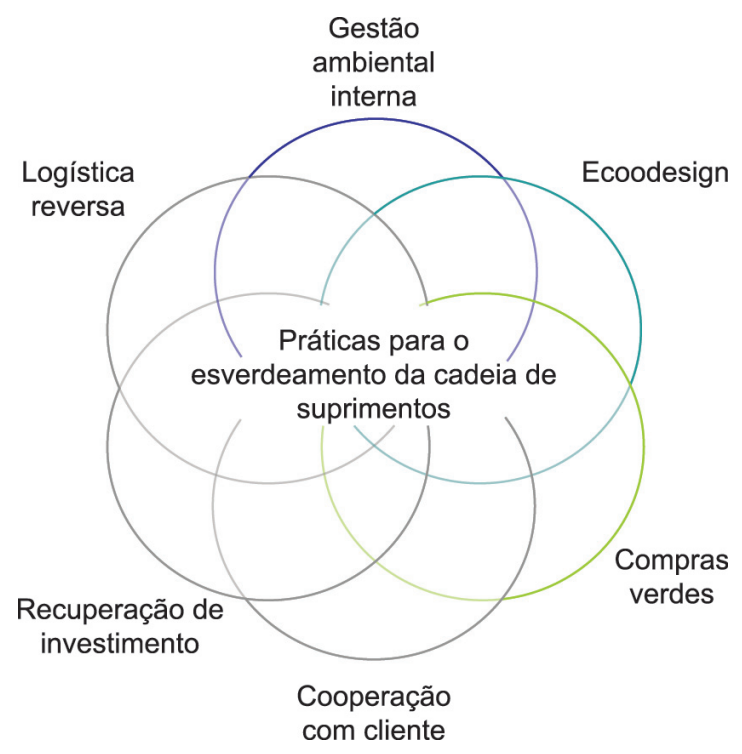

Figura 1. Práticas de GSCM utilizadas nesta pesquisa. alta administração) são as práticas mais importantes para implementação de GSCM. De forma a reforçar a importância dos fornecedores no processo de GSCM, Bai e Sarkis (2010) e Zailani et al. (2012) afirmam que compras verdes afetam o desempenho da empresa. No entanto, Azevedo, Carvalho e Cruz-Machado (2011) e Zhu, Sarkis e Lai (2007) ponderam a importância de compras verdes, uma vez que essa tem menor prioridade, porque geralmente requer a participação das organizações dominantes (maior poder de barganha).

Depois da compreensão do conceito de GSCM e de suas práticas, apresenta-se a metodologia da pesquisa realizada.

\section{Bases metodológicas desta pesquisa}

O setor eletroeletrônico foi escolhido para ser estudado nesta pesquisa por ser um setor bastante estudado no tema de GSCM (JABBOUR; ARANTES; JABBOUR, 2013), principalmente no contexto de países em desenvolvimento, como a China (ZHU; SARKIS, 2004, 2006; ZHU; SARKIS; LAI, 2007, 2012a, b), sendo interessante também estudá-lo no contexto de outro país em desenvolvimento, como o Brasil, e pelo fato de este setor ser um dos que tende a ser afetado pela PNRS.

Os critérios de seleção das empresas a serem pesquisadas foram: (a) importância relativa das empresas em seus segmentos de mercado (informática) e (b) permissão de acesso à empresa e a dados detalhados para compor a pesquisa.

$\mathrm{O}$ roteiro de pesquisa foi elaborado de acordo com os principais conceitos da revisão de literatura apresentada na Seção 2. Esse roteiro se dedicou à caracterização das práticas de GSCM adotadas.

No Quadro 1, está detalhado o processo de coleta de dados, que foi realizado em 2012 e desenvolvido por meio de triangulação de dados com entrevistas, observações diretas feitas no local e obtenção de dados secundários. A aplicação do roteiro com os profissionais das empresas considerou também contatos posteriores a fim de esclarecer eventuais dúvidas. Para um completo entendimento da realidade, buscou-se entrevistar no mínimo dois funcionários por empresa. Durante as visitas às empresas estudadas, foram realizadas observações diretas tanto na linha de produção como em áreas relativas à separação de resíduos, quando disponível. Também foram coletados diversos dados secundários.

Durante as entrevistas, alguns dos autores deste trabalho, presentes na pesquisa de campo, foram realizando anotações das respostas dos entrevistados e dos documentos apresentados. Depois da conclusão da pesquisa de campo, cada autor realizou uma descrição analítica do caso. Estes documentos de descrição do caso foram comparados a fim de gerar um documento único claro e rico em detalhes. 
Quadro 1. Caracterização das oito empresas pesquisadas e dos dados coletados.

\begin{tabular}{|c|c|c|c|c|}
\hline Empresa & Caracterização & Entrevista & $\begin{array}{c}\text { Observação } \\
\text { (duração) }\end{array}$ & Dados Secundários \\
\hline $\mathbf{A}$ & $\begin{array}{l}\text { Montadora multinacional } \\
\text { de impressoras, projetores e } \\
\text { derivados. } \\
\text { Sua filial no Brasil é de médio } \\
\text { porte e há montagem somente } \\
\text { de impressoras matricial e } \\
\text { fiscal, sendo o restante dos } \\
\text { produtos importados da sua } \\
\text { matriz. }\end{array}$ & $\begin{array}{l}\text { - Coordenador } \\
\text { ambiental } \\
\text { - Engenheiro de } \\
\text { manufatura }\end{array}$ & $\begin{array}{l}\text { Uma visita com } \\
\text { duração de } 3 \\
\text { horas e meia }\end{array}$ & $\begin{array}{l}\text { - Apresentação em power } \\
\text { point de programas de } \\
\text { sustentabilidade e objetivos } \\
\text { de melhoria ambiental } \\
\text { - Folder interno da empresa } \\
\text { com sua política de gestão } \\
\text { ambiental } \\
\text { - Dados contidos no website } \\
\text { da empresa e da matriz }\end{array}$ \\
\hline B & $\begin{array}{l}\text { Montadora/fabricante } \\
\text { nacional de grande porte } \\
\text { de computadores (desktop), } \\
\text { notebooks, netbooks, tablets } \\
\text { e outros. } \\
\text { Líder de fabricação e vendas } \\
\text { de computadores no Brasil. }\end{array}$ & $\begin{array}{l}\text { - } \text { Coordenador de } \\
\text { sustentabilidade } \\
\text { - Engenheiro de } \\
\text { qualidade }\end{array}$ & $\begin{array}{l}\text { Uma visita com } \\
\text { duração de } 2 \\
\text { horas e meia }\end{array}$ & $\begin{array}{l}\text { - Dados contidos da intranet } \\
\text { - Dados sobre projetos } \\
\text { ambientais } \\
\text { - Documentos disponíveis no } \\
\text { website da empresa }\end{array}$ \\
\hline C & $\begin{array}{l}\text { Montadora multinacional } \\
\text { de computadores (desktop) } \\
\text { e notebooks. Sua atuação é } \\
\text { recente no mercado brasileiro. } \\
\text { Sua estratégia é terceirizar } \\
\text { todo o processo produtivo, } \\
\text { contratando e gerenciando } \\
\text { empresas montadoras. }\end{array}$ & $\begin{array}{l}\text { Engenheiro } \\
\text { de higiene e } \\
\text { segurança do } \\
\text { trabalho } \\
\text { - Gerente de } \\
\text { projetos }\end{array}$ & $\begin{array}{l}\text { Uma visita ao } \\
\text { escritório com } \\
\text { duração de } 3 \\
\text { horas }\end{array}$ & $\begin{array}{l}\text { - Dados e informações } \\
\text { disponíveis no website da } \\
\text { empresa e da matriz }\end{array}$ \\
\hline D & $\begin{array}{l}\text { Montadora/fabricante } \\
\text { nacional de grande porte de } \\
\text { desktops, notebooks, netbooks, } \\
\text { automação bancária e serviços } \\
\text { tecnológicos. } \\
\text { Exporta e possui subsidiárias } \\
\text { no exterior. }\end{array}$ & - Analista ambiental & $\begin{array}{l}\text { Uma visita com } \\
\text { duração de } 4 \\
\text { horas e meia }\end{array}$ & $\begin{array}{l}\text { - Dados disponíveis no } \\
\text { website da empresa } \\
\text { sobre o programa de } \\
\text { sustentabilidade, política } \\
\text { ambiental, manual do } \\
\text { usuário consciente e } \\
\text { informações sobre os } \\
\text { requisitos legais que a } \\
\text { empresa cumpre. }\end{array}$ \\
\hline $\mathbf{E}$ & $\begin{array}{l}\text { Contratada multinacional de } \\
\text { grande porte para montagem } \\
\text { de impressoras, notebooks, } \\
\text { computadores, tablets, } \\
\text { máquina de cartão de crédito, } \\
\text { celulares e outros para } \\
\text { empresas (cliente) de Marca } \\
\text { de renome. }\end{array}$ & $\begin{array}{l}\text { - Supervisor } \\
\text { ambiental } \\
\text { - Coordenador de } \\
\text { projetos } \\
\text { - Analista de } \\
\text { sistemas }\end{array}$ & $\begin{array}{l}\text { Uma visita com } \\
\text { duração de } 6 \\
\text { horas e meia }\end{array}$ & $\begin{array}{l}\text { - Dados e informações } \\
\text { contidos na intranet, } \\
\text { apresentação em power point } \\
\text { sobre projetos, programas } \\
\text { e resultados ambientais que } \\
\text { a empresa desenvolve com } \\
\text { seus fornecedores e clientes } \\
\text { - Folder interno sobre a } \\
\text { política, missão, objetivos e } \\
\text { ações ambientais da empresa } \\
\text { - Dados disponíveis no } \\
\text { website da empresa }\end{array}$ \\
\hline $\mathbf{F}$ & $\begin{array}{l}\text { Contratada multinacional de } \\
\text { grande porte para montagem } \\
\text { de impressoras, cartuchos, } \\
\text { toner, leitor de documentos, } \\
\text { máquina de cartão de crédito, } \\
\text { entre outros para empresas } \\
\text { (cliente) de Marca de renome. }\end{array}$ & $\begin{array}{l}\text { - Assistente de } \\
\text { Qualidade } \\
\text { - Analista de } \\
\text { Qualidade } \\
\text { - Auxiliar de } \\
\text { Qualidade }\end{array}$ & $\begin{array}{l}\text { Uma visita com } \\
\text { duração de } 3 \\
\text { horas }\end{array}$ & $\begin{array}{l}\text { - Documentos disponíveis no } \\
\text { website da empresa } \\
\text { - Folder sobre a semana da } \\
\text { gestão ambiental oferecida } \\
\text { aos funcionários } \\
\text { - Folder sobre a política, } \\
\text { missão e objetivos } \\
\text { ambientais }\end{array}$ \\
\hline
\end{tabular}


Quadro 1. Continuação...

\begin{tabular}{|c|c|c|c|c|}
\hline Empresa & Caracterização & Entrevista & $\begin{array}{c}\text { Observação } \\
\text { (duração) }\end{array}$ & Dados Secundários \\
\hline $\mathbf{G}$ & $\begin{array}{l}\text { Montadora/fabricante } \\
\text { multinacional de grande } \\
\text { porte de desktop, servidor, } \\
\text { notebooks, netbooks, } \\
\text { ultrabooks, all-in-ones. }\end{array}$ & $\begin{array}{l}\text { - Coordenadora } \\
\text { de projeto de } \\
\text { responsabilidade } \\
\text { social e ambiental } \\
\text { na cadeia de } \\
\text { suprimentos }\end{array}$ & $\begin{array}{l}\text { Uma visita com } \\
\text { duração de } 3 \\
\text { horas }\end{array}$ & $\begin{array}{l}\text { - Informações e documentos } \\
\text { disponíveis no website } \\
\text { da empresa sobre } \\
\text { sustentabilidade, política, } \\
\text { missão e objetivos } \\
\text { ambientais } \\
\text { - Dados fornecidos da } \\
\text { intranet e documentos em } \\
\text { power point sobre ações } \\
\text { ambientais internas, com } \\
\text { seus fornecedores e com } \\
\text { clientes } \\
\text { Folder sobre a política, } \\
\text { missão e objetivo ambiental } \\
\text { da empresa }\end{array}$ \\
\hline H & $\begin{array}{l}\text { Contratada multinacional de } \\
\text { grande porte para montagem } \\
\text { de notebooks, netbooks, } \\
\text { desktops, tablets, entre outros } \\
\text { para empresas (cliente) de } \\
\text { Marca de renome. } \\
\text { É a maior empresa de } \\
\text { manufatura eletrônica } \\
\text { contratada. }\end{array}$ & $\begin{array}{l}\text { - Analista de } \\
\text { qualidade } \\
\text { - Engenheiro de } \\
\text { qualidade }\end{array}$ & $\begin{array}{l}\text { Uma visita com } \\
\text { duração de } 2 \\
\text { horas e meia }\end{array}$ & $\begin{array}{l}\text { - Informações disponíveis } \\
\text { no website da matriz } \\
\text { sobre a gestão e a política } \\
\text { ambiental } \\
\text { - Folder sobre a política e } \\
\text { objetivos ambientais da } \\
\text { empresa }\end{array}$ \\
\hline
\end{tabular}

Assim, para cada caso, fazia-se uma análise individual com o objetivo de estruturar, reduzir e contextualizar informações. Na sequência, fazia-se a análise cruzada entre os casos a fim de detectar comunalidades e diferenças nos padrões da adoção de práticas de GSCM.

A análise dos resultados foi feita por meio da sistematização e tabulação dos dados cruzados entre os casos para posterior comparação desses resultados com os conceitos apresentados na Seção 2.

\section{Resultados e discussões}

O Quadro 2 apresenta os principais resultados identificados quanto à adoção de práticas de GSCM nas oito empresas estudadas.

Todas as empresas estudadas seguem dois padrões internacionais: (a) processos de soldagem sem chumbo (lead free) e (b) diretiva Europeia RoHS (Restriction of Hazardous Substances), que consiste na restrição do uso de substâncias perigosas na produção de produtos eletroeletrônicos. Isto se justifica pelo fato de as empresas estudadas serem filiais de multinacionais e/ou por exportarem seus produtos para mercados europeus.

De uma forma geral, as empresas de alta tecnologia atuantes no Brasil têm empreendido ações para adotar muitas das práticas de GSCM consideradas neste estudo. Gestão ambiental interna e recuperação de investimentos, em especial, são empregadas por todas as empresas analisadas que possuem unidades produtivas, corroborando com os indicativos de Zhu e Sarkis (2004, 2006), Hoejmose, Brammer e Millington (2012) e Zhu, Sarkis e Lai (2012b). A gestão ambiental interna tem sido alcançada pelas empresas a partir da certificação ISO 14001, e do estabelecimento de metas ambientais para a fábrica, tais como, redução do consumo de energia e água, e de geração de $\mathrm{CO}_{2} \mathrm{e}$ resíduos. Dois casos (Empresas D e F) têm realizado treinamentos e palestras de conscientização do uso racional de recursos para seus funcionários, e a empresa E possui um software de acompanhamento de requisitos técnicos e legais estabelecidos pelo cliente. A recuperação de investimentos tem sido realizada a partir da venda de, principalmente, sucata e de materiais usados para empresas recicladoras homologadas e avaliadas anualmente.

A logística reversa tem sido também uma prática de GSCM considerada pelas empresas de alta tecnologia situadas no Brasil. Três empresas não realizam a logística reversa $(\mathrm{E}, \mathrm{F}$ e H), pois elas são as manufaturas contratadas e as responsáveis pela logística reversa são as empresas clientes. Uma das justificativas para adoção da logística reversa é que no Brasil, por meio da Nova Política Nacional de Resíduos Sólidos, as empresas são responsáveis pela logística reversa de seus produtos no pós-consumo e 


\begin{tabular}{|c|c|c|c|c|c|c|}
\hline $\mathbf{I}$ & 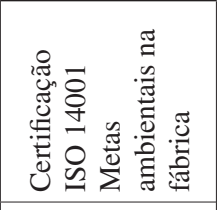 & 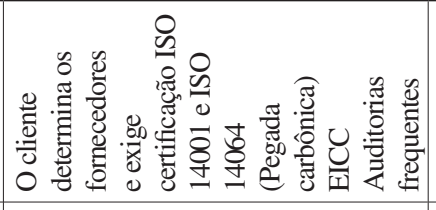 & & 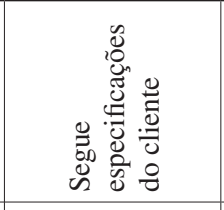 & 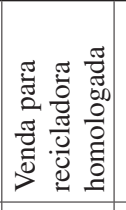 & 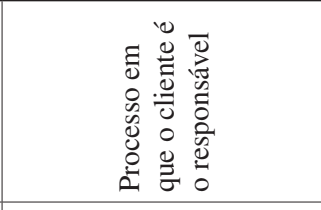 \\
\hline | U & 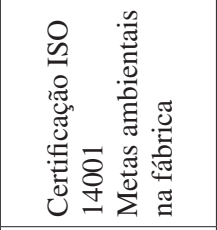 & 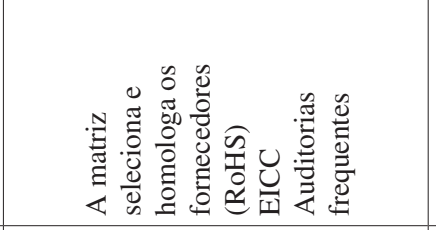 & 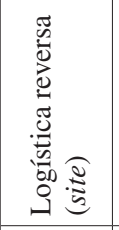 & 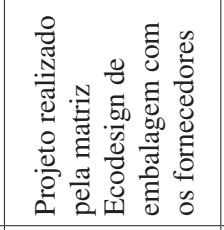 & 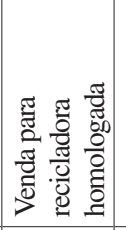 & 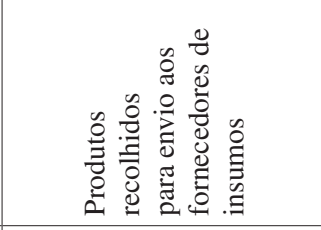 \\
\hline E & 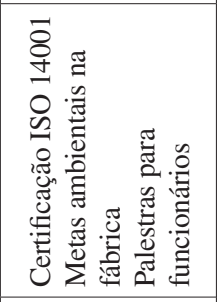 & 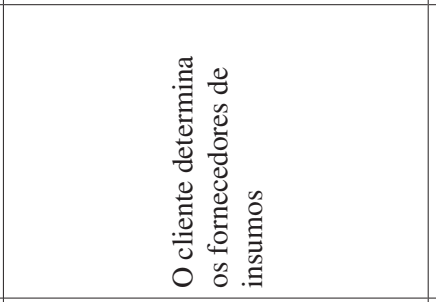 & & 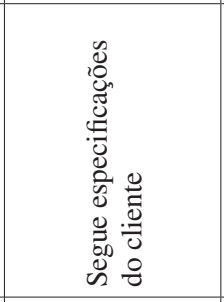 & 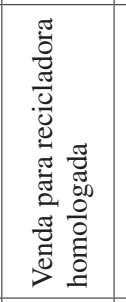 & 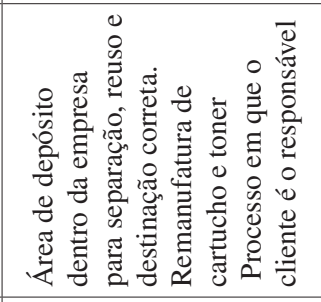 \\
\hline 되 & 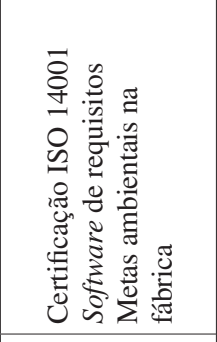 & 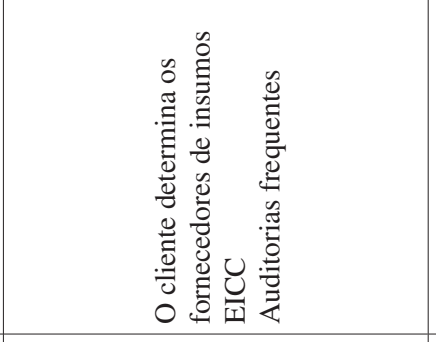 & 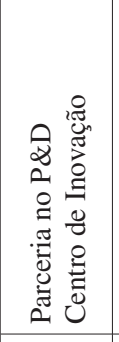 & 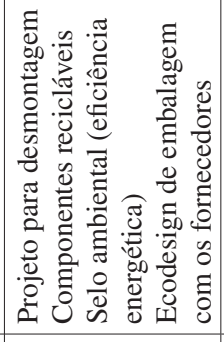 & 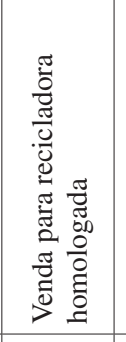 & 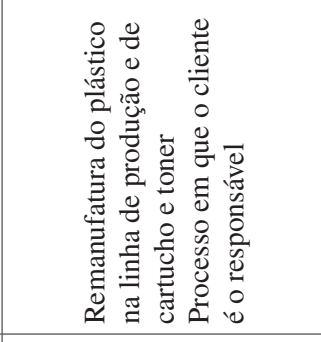 \\
\hline$\theta$ & 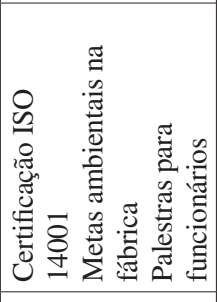 & 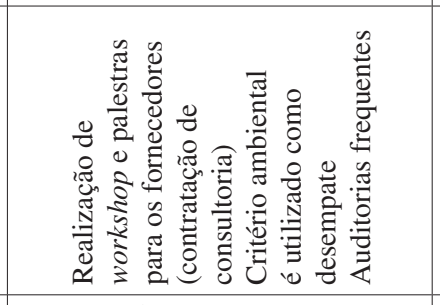 & 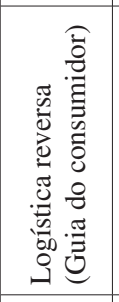 & $\begin{array}{l}\mathscr{2} \\
\text { व } \\
\varkappa\end{array}$ & 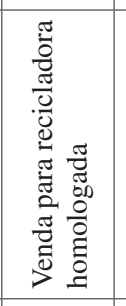 & 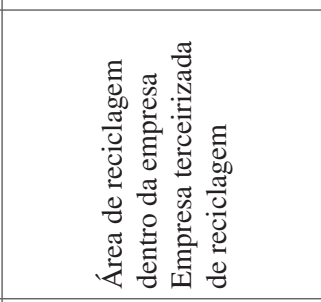 \\
\hline u & 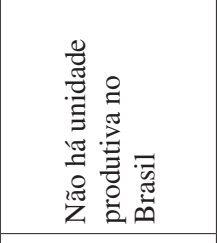 & 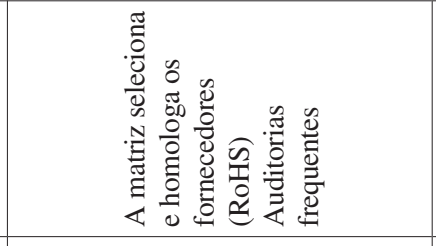 & 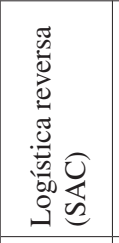 & 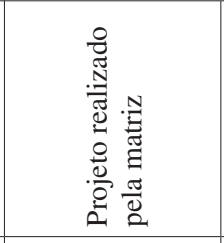 & & \\
\hline 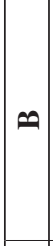 & 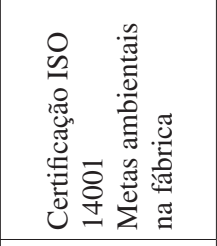 & 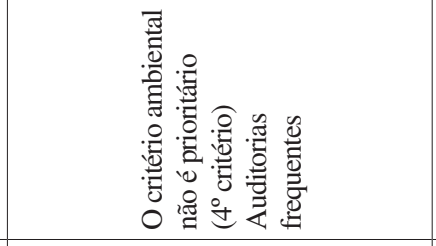 & 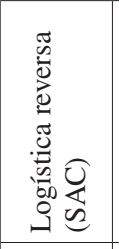 & 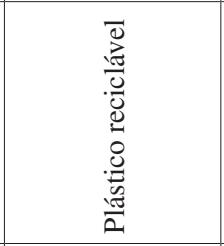 & 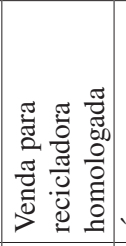 & 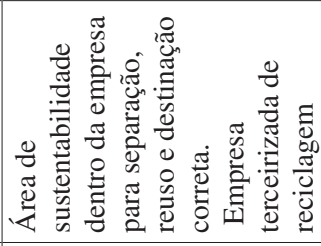 \\
\hline$\varangle$ & 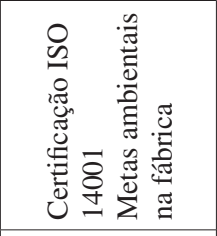 & 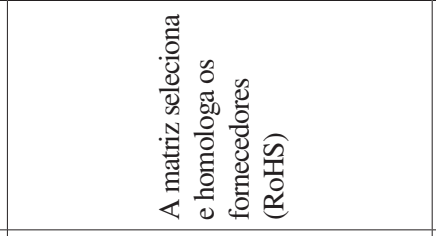 & 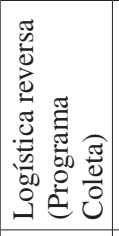 & 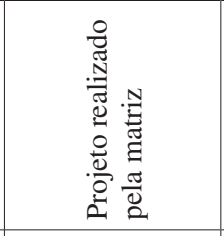 & 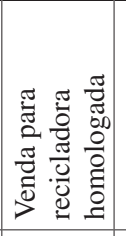 & 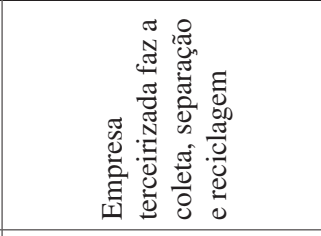 \\
\hline 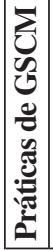 & 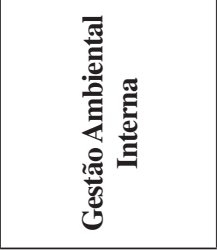 & 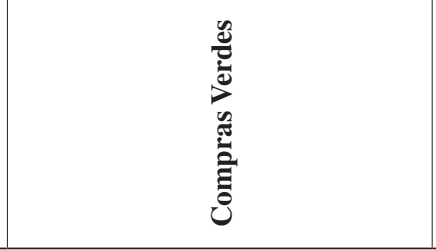 & 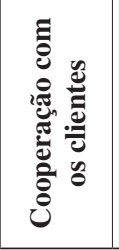 & 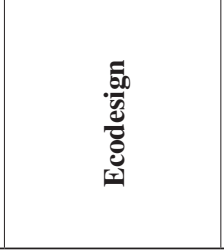 & 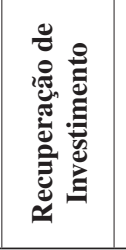 & 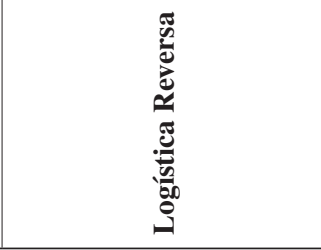 \\
\hline
\end{tabular}


da reinserção na cadeia produtiva e, em caso contrário, pode haver penalidades (ex.: pagamento de multas). Portanto, por exemplo, empresas como B, D e F possuem uma área dentro da empresa destinada à separação, reuso e destinação correta dos materiais utilizados no processo de produção. Alternativa e complementarmente, empresas como A, B, D e G contratam uma empresa recicladora para recolher os produtos pós-consumo junto as suas assistências técnicas para o devido processamento. A empresa $\mathrm{G}$, por exemplo, retorna certos materiais para seus fornecedores de $1^{\mathrm{a}}$ camada.

A prática de cooperação com o cliente tem sido uma prática de GSCM que tem apoiado muito a prática de logística reversa. As empresas A, B, C, D e G, por exemplo, têm anunciado em seus sites eletrônicos programas (ex.: "Programa Coleta" e "Guia do Consumidor") para facilitar a devolução dos produtos pós-consumo pelos consumidos. Os consumidores podem levar produtos usados para a assistência técnica ou ligar no Serviço de Apoio ao Consumidor (SAC) para que uma empresa terceirizada retire o produto diretamente na casa do consumidor. No entanto, há várias outras formas de fazer a cooperação com o cliente, por exemplo, no ecodesign, na produção mais limpa, e no uso de embalagens verdes, mas apenas a empresa $E$ interage com o cliente para o propósito do ecodesign. A empresa $\mathrm{E}$ possui um centro de Pesquisa e Desenvolvimento (P\&D) dedicado a propor soluções de produtos ambientalmente adequados aos seus clientes ou trabalhar em codesenvolvimento de produtos com os clientes.

Há aspectos estruturais das cadeias de suprimentos das empresas estudadas que afetam diretamente a forma como as práticas de compras verdes e ecodesign são desenvolvidas: relação entre matriz e filial e manufatura contratada.

Quanto à prática de ecodesign, as empresas multinacionais que são donas da marca (A, C e G) reproduzem no Brasil os projetos de produtos planejados na matriz de suas empresas. Portanto, na unidade localizada no Brasil, não há desenvolvimento de produtos. Vale ressaltar que, nas matrizes dessas empresas, há projetos de produtos visando à eficiência energética, redução de substâncias tóxicas (RoHS) nos insumos de seus produtos, reciclabilidade das partes dos produtos e fácil desmontagem. As manufaturas contratadas (E, F e H) tendem a seguir os requisitos de projetos estabelecidos pelos clientes. Ou seja, se o cliente considera a variável ambiental estratégia em seu negócio, isto tende a afetar o produto manufaturado pela empresa contratada. A empresa E, em especial, é um exemplo. Ela possui um centro de P\&D exclusivo para projetar produtos para seus clientes. As características dos produtos são: fáceis de desmontar, componentes recicláveis e selo ambiental (de eficiência energética). E, as empresas nacionais,
B e D, estão iniciando ações de ecodesign, como o uso de insumo reciclável (a partir de um estudo de análise de ciclo de vida) e restrição de substâncias danosas (RoHS), para incorporar ações ambientais no projeto de produto.

Quanto à prática de compras verdes, as empresas multinacionais que são donas da marca (A, C e G) não selecionam seus fornecedores de insumos, com exceção dos de embalagem. É a empresa matriz que seleciona e homologa os fornecedores (com base nos critérios da RoHS) e as filiais brasileiras são responsáveis por realizar auditorias frequentes para checar o cumprimento de requisitos das matrizes. A empresa $\mathrm{G}$, adicionalmente, desenvolve projeto de ecodesign com fornecedores de embalagem e monitora os fornecedores homologados pela matriz com base no código de conduta socioambiental do EICC (Electronic Industry Citizenship Coalition). O EICC estabelece normas para assegurar que as condições de trabalho da cadeia de suprimentos da indústria eletrônica são seguras, que os funcionários são tratados com respeito e dignidade, e que as atividades empresariais são conduzidas de forma ética e responsável do ponto de vista ambiental. No caso das manufaturas contratadas (E, F e H), o cliente (empresa que detém a marca) determina os fornecedores de insumos. As empresas E e H realizam auditorias frequentes nos fornecedores indicados e o fazem com base no EICC. A empresa E desenvolve projeto de ecodesign com fornecedores de embalagem e a empresa $\mathrm{H}$ trabalha com fornecedores certificados pela ISO 14001 e ISO 14064 (pegada carbônica). $\mathrm{E}$, as empresas nacionais, B e D, selecionam fornecedores com base em critérios ambientais, mas, no caso da empresa $\mathrm{B}$, este critério não é prioritário ( $4^{\circ}$ lugar), em detrimento dos critérios tradicionais (custo, entrega e qualidade) e no caso da empresa $\mathrm{D}$, ela encontra dificuldade de selecionar empresas habilitadas para fornecer insumos ambientalmente adequados, portanto, ela mesma desenvolve seus fornecedores com o suporte de uma empresa de consultoria realizando workshops e palestras, além de auditar seus fornecedores frequentemente.

Segundo Zhu, Sarkis e Lai (2012a), a adequada implementação sequencial de práticas internas e externas de GSCM pode apoiar as organizações a acumularem benefícios ambientais, econômicos e operacionais. No caso das empresas de alta tecnologia localizadas no Brasil, elas possuem ações muito semelhantes quanto à prática de gestão ambiental interna (práticas internas de GSCM) e estas parecem estar consolidadas. Já as demais práticas, recuperação de investimentos, logística reversa, cooperação com cliente, ecodesign e compras verdes, estão em desenvolvimento, com destaque para recuperação de investimentos e logística reversa. Portanto, as empresas estudadas tendem a buscar ao longo do 
tempo melhor desempenho ambiental, econômico e operacional, uma vez que estão adotando as práticas de forma paulatina e com destaque para as práticas internas de GSCM.

No entanto, segundo Zhu, Sarkis e Lai (2012b), as empresas estudadas ainda não estão sendo completamente proativas, pois, segundo esses autores, as empresas são proativas em termos de adoção de práticas de GSCM quando, além de terem iniciativas consolidadas de gestão ambiental interna e recuperação de investimentos, possuem ações de ecodesign. Em função de questões estruturais da cadeia de suprimentos das empresas estudadas, o ecodesign tem sido adotado de forma mais estruturada apenas pela empresa E. Questões como relação matriz e filial e manufatura contratada dificultam a independência das empresas localizadas no Brasil de projetarem seus próprios produtos, por isso, são poucas as iniciativas de ecodesign realizadas no Brasil.

Ainda, quanto à estrutura da cadeia de suprimentos das empresas estudadas, as práticas de compras verdes ocorrem mais por iniciativas das matrizes do que das filiais brasileiras. O mesmo ocorre com as contratadas, pois dependem das indicações de seus clientes. Isto pode ser justificado por Azevedo, Carvalho e Cruz-Machado (2011) e Zhu, Sarkis e Lai (2007), que ponderam a importância de compras verdes, uma vez que essa tem menor prioridade, porque geralmente requer a participação das organizações com maior poder de barganha.

\section{Conclusões}

\subsection{Principais contribuições do estudo}

Esta pesquisa teve como objetivo identificar e analisar como as práticas de GSCM estão sendo adotadas em empresas de alta tecnologia localizadas no Brasil. O objetivo foi alcançado a partir de estudos de casos em oito empresas representativas do setor.

Como principais resultados, pode-se destacar:

- As práticas de GSCM mais adotadas nas empresas estudadas de alta tecnologia localizadas no Brasil são: gestão ambiental interna, recuperação de investimentos e logística reversa.

- A adoção de práticas de ecodesign e compras verdes estão condicionadas a iniciativas das matrizes das empresas estudadas e das empresas clientes das manufaturas contratadas.

- Como consequência dos itens anteriores, vale destacar que a legislação ambiental brasileira (Nova Política Nacional de Resíduos Sólidos) e as diretivas internacionais, como a RoHS e o IECC, são muito importantes para impulsionar a adoção de práticas de GSCM.
- A cooperação com o cliente é ainda tímida, pois ocorre apenas como apoio à prática de logística reversa, no entanto, ela poderia ocorrer de diferentes formas, como no ecodesign, na produção mais limpa e na embalagem retornável.

- As empresas estudadas ainda não podem ser consideradas proativas, pela falta de ações mais estruturadas do ecodesign realizado no Brasil, por outro lado, elas tendem a alcançar benefícios ambientais, econômicos e operacionais, pois estão buscando uma adoção sequencial entre as práticas internas e externas de GSCM.

\subsection{Diretrizes para implementação de práticas de GSCM}

Com base nessas constatações, este artigo traz algumas diretrizes de como gestores de empresas similares às estudadas nesta pesquisa podem proceder para incorporar iniciativas de GSCM, uma vez que ações em prol de GSCM é um processo eventualmente novo para empresas brasileiras ou localizadas no Brasil:

- Gestão ambiental interna pode ser praticada por meio de certificação ISO 14001, criação de metas ambientais para a fábrica e fornecimento de palestras de conscientização para os funcionários.

- Compras verdes podem ser estabelecidas por meio da seleção de fornecedores com base na RoHS, em certificações ISO e na realização de auditorias ambientais.

- Cooperação com o cliente, que tem sido fundamental para a logística reversa, solicitada na Nova Política de Resíduos Sólidos do Brasil, pode ocorrer por meio do suporte de SAC e de programas de destinação correta (site da empresa).

- Ecodesign pode ser facilitado por meio de colaboração entre a empresa, cliente e criação de centros de P\&D.

- Logística reversa pode ser concretizada com o apoio de empresas terceirizadas e a instalação de uma área na empresa com o objetivo de separação, reuso e destinação correta dos materiais utilizados no processo de produção.

Estas diretrizes são bem exploratórias e devem ser utilizadas considerando-se as limitações que possui esta pesquisa, ou seja, análise apenas do contexto brasileiro e apenas de empresas do setor de alta tecnologia, e forte ênfase nas informações passadas pelos entrevistados.

Como pesquisas futuras, sugere-se verificar como empresas de outros setores, os menos afetados pela 
PNRS, têm adotado práticas de GSCM e comparar os resultados com os desta pesquisa.

\section{Referências}

AZEVEDO, S. G.; CARVALHO, H.; CRUZ-MACHADO, $\mathrm{V}$. The influence of green practices on supply chain performance: a case study approach. Transportation Research Part E, v. 47, n. 6, p. 850-871, 2011. http:// dx.doi.org/10.1016/j.tre.2011.05.017

BAI, C.; SARKIS, J. Green supplier development: analytical using rough set theory. Journal of Cleaner Production, v. 18, n. 12, p. 1200-1210, 2010. http:// dx.doi.org/10.1016/j.jclepro.2010.01.016

BRASIL. Lei ${ }^{\circ} 12.305$, de 2 de agosto de 2010. Institui a Política Nacional de Resíduos Sólidos; altera a Lei $n^{\circ} 9.605$, de 12 de fevereiro de 1998; e dá outras providências. Diário Oficial da República Federativa do Brasil, Brasília, DF, 3 ago. 2010. Seção 1, p. 3.

BRITO, R. P.; BERARDI, P. C. Vantagem competitiva na gestão sustentável da cadeia de suprimentos: um metaestudo. Revista de Administração de Empresas, v. 50, n. 2, p. 155-169, 2010. http://dx.doi.org/10.1590/ S0034-75902010000200003

DIABAT, A.; GOVINDAN, K. An analysis of the drivers affecting the implementation of green supply chain management. Resources, Conservation and Recycling, v. 55, n. 6, p. 659-667, 2011. http://dx.doi.org/10.1016/j. resconrec.2010.12.002

DIAS, S. L. F. G., LABEGALINI, L.; CSILLAG, J. M. Sustentabilidade e cadeia de suprimentos: uma perspectiva comparada de publicações nacionais e internacionais. Produção, v. 22, n. 3, p. 517-533, 2012. http://dx.doi.org/10.1590/S0103-65132012005000034

ELTAYEB, T. K.; ZAILANI, S.; RAMAYAH, T. Green supply chain initiatives among certified companies in Malaysia and environmental sustainability: investigating the outcomes. Resources, Conservation and Recycling, v. 55, n. 5, p. 495-506, 2011. http://dx.doi.org/10.1016/j. resconrec.2010.09.003

GOLICIC, S. L.; SMITH, C. D.; A meta analysis of environmentally sustainable supply chain management practices and firm performance. Journal of Supply Chain Management, v. 49, n. 2, p. 78-95, 2013. http:// dx.doi.org/10.1111/jscm. 12006

GOVINDAN, K.; CHENG, T. C. E. Environmental supply chain management. Resources, Conservation and Recycling, v. 55, n. 6, p. 557-558, 2011. http://dx.doi. org/10.1016/j.resconrec.2011.04.006

GREEN JUNIOR, K. W. et al. Green supply chain management practices: impact on performance. Supply Chain Management: An International Journal, v. 17, n. 3, p. 290-305, 2012. http://dx.doi. org/10.1108/13598541211227126

HOEJMOSE, S.; BRAMMER, S.; MILLINGTON, A. "Green" supply chain management: the role of trust and top management in B2B and B2C markets. Industrial Marketing Management, v. 41, n. 4, p. 609-620, 2012. http://dx.doi.org/10.1016/j.indmarman.2012.04.008

HSU, C. W.; HU, A. H. Green supply chain management in the electronic industry. International Journal of
Environmental Science and Technology, v. 5, n. 2, p. 205-216, 2008. http://dx.doi.org/10.1007/BF03326014 JABBOUR, A. B. L. S.; ARANTES, A. F.; JABBOUR, C. J. C. Green supply chain management: mapping the territory. International Journal of Environment and Sustainable Development, v. 12, n. 1, p. 145-167, 2013. http://dx.doi.org/10.1504/IJESD.2013.052975

LAI, K. H.; WONG, C. W. Green logistics management and performance: Some empirical evidence from Chinese manufacturing exporters. Omega, v. 40, n. 3, p. 267-282, 2012. http://dx.doi.org/10.1016/j. omega.2011.07.002

MARTÍ, J. M. C.; SEIFERT, R. W. Assessing the comprehensiveness of supply chain environmental strategies. Business Strategy and the Environment, v. 22, n. 5, p. 339-356, jul. 2013. http://dx.doi. org/10.1002/bse. 1749

MIN, H.; GALLE, W. P. Green purchasing practices of US firms. International Journal of Operations \& Production Management, v. 21, n. 9, p. 1222-1238, 2001. http://dx.doi.org/10.1108/EUM0000000005923

SARKIS, J. A strategic decision framework for green supply chain management. Journal of Cleaner Production, v. 11, n. 4, p. 397-409, 2003. http://dx.doi.org/10.1016/ S0959-6526(02)00062-8

SARKIS, J.; ZHU, Q.; LAI, K. H. An organizational theoretic review of green supply chain management literature. International Journal of Production Economics, v. 130, n. 1, p. 1-15, 2011. http://dx.doi.org/10.1016/j. ijpe.2010.11.010

SEURING, S. et al. Sustainability and supply chain management: an introduction to the special issue. Journal of Cleaner Production, v. 16, n. 15, p. 1545-1551, 2008. http://dx.doi.org/10.1016/j.jclepro.2008.02.002

SHERIFF, K. M. M.; GUNASEKARAN, A.; NACHIAPPAN, S. Reverse logistics network design: a review on strategic perspective. International Journal of Logistics Systems and Management, v. 12, n. 2, p. 171-194, 2012. http:// dx.doi.org/10.1504/IJLSM.2012.047220

SRIVASTAVA, S. K. Green supply-chain management: A state-of-the-art literature review. International Journal of Management Review, v. 9, n. 1, p. 53-80, 2007. http://dx.doi.org/10.1111/j.1468-2370.2007.00202.x

VACHON, S.; KLASSEN, R. D. Extending green practices across the supply chain: the impact of upstream and downstream integration. International Journal of Operations \&Production Management, v. 26, n. 7, p. 795-821, 2006. http://dx.doi. org/10.1108/01443570610672248

VACHON, S.; KLASSEN, R. D. Environmental management and manufacturing performance: the role of collaboration in the supply chain. International Journal of Production Economics, v. 111, p. 299-315, 2008. http://dx.doi. org/10.1016/j.ijpe.2006.11.030

ZAILANI, S. et al. Sustainable supply chain management (SSCM) in Malaysia: a survey. International Journal of Production Economics, v. 140, n. 1, p. 330-340, 2012. http://dx.doi.org/10.1016/j.ijpe.2012.02.008

ZHU, Q. et al. Firm-level correlates of emergent green supply chain management practices in the Chinese context. Omega, v. 36, p. 577-591, 2008. http://dx.doi. org/10.1016/j.omega.2006.11.009 
ZHU, Q.; SARKIS, J. Relationships between operational practices and performance among early adopters of green supply chain management practices in Chinese manufacturing enterprises. Journal of Operations Management, v. 22, n. 3, p. 265-289, 2004. http:// dx.doi.org/10.1016/j.jom.2004.01.005

ZHU, Q.; SARKIS, J. An inter-sectoral comparison of green supply chain management in China: Drivers and practices. Journal of Cleaner Production, v. 14, n. 5, p. 472-486, 2006. http://dx.doi.org/10.1016/j. jclepro.2005.01.003

ZHU, Q.; SARKIS, J.; LAI, K-H. Green supply chain management: pressures, practices and performance within the Chinese automobile industry. Journal of Cleaner Production, v. 15, n. 11-12, p. 1041-1052, 2007. http:// dx.doi.org/10.1016/j.jclepro.2006.05.021

ZHU, Q.; SARKIS, J.; LAI, K-H. Confirmation of a measurement model for green supply chain management practices implementation. International Journal of
Production Economics, v. 111, n. 2, p. 261-273, 2008. http://dx.doi.org/10.1016/j.ijpe.2006.11.029

ZHU, Q.; SARKIS, J.; LAI, K-H. Examining the effects of Green supply chain management practices and their mediations on performance improvements. International Journal of Production Research, v. 5, n. 5, p. 1377 1394, 2012a. http://dx.doi.org/10.1080/00207543.20 11.571937

ZHU, Q.; SARKIS, J.; LAI, K-H. Green supply chain management innovation diffusion and its relationship to organizational improvement: An ecological modernization perspective. Journal of Engineering and Technology Management, v. 29, n. 1, p. 168-185, 2012b. http:// dx.doi.org/10.1016/j.jengtecman.2011.09.012

ZSIDISIN, G. A.; SIFERD, S. P. Environmental purchasing: a framework for theory development. European Journal of Purchasing \& Supply Management, v. 7, n. 1, p. 61-73, 2001. http://dx.doi.org/10.1016/ S0969-7012(00)00007-1 